\title{
STEPPER MOTOR BASED MOdEL OF ELECTRIC DRIVE FOR THROTTLE VALVE
}

\author{
Levon Gevorkov, Václav Šmídl, Martin Sirový
}

Department of Electrical Engineering, University of West Bohemia (UWB), Pilsen, Czech Republic
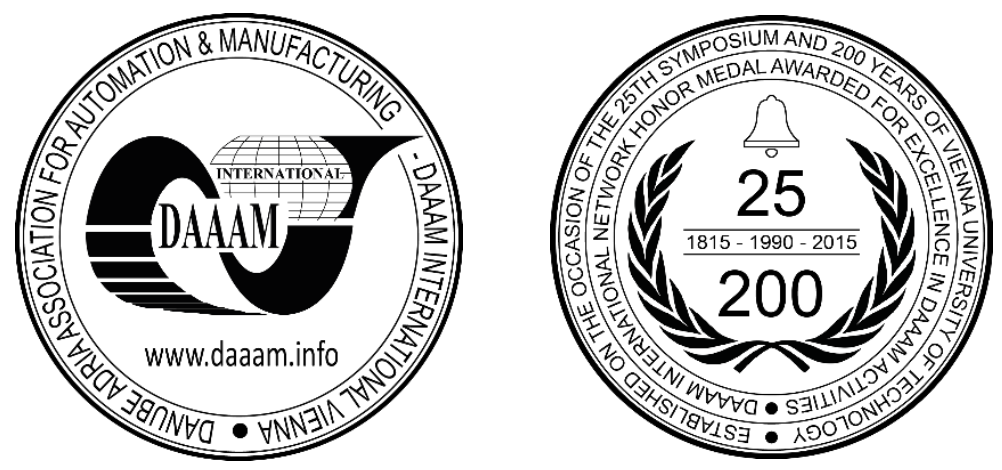

This Publication has to be referred as: Gevorkov, L[evon]; Smidl, V[aclav] \& Sirovy, M[artin] (2018). Stepper Motor Based Model of Electric Drive for Throttle Valve, Proceedings of the 29th DAAAM International Symposium, pp.11021107, B. Katalinic (Ed.), Published by DAAAM International, ISBN 978-3-902734-20-4, ISSN 1726-9679, Vienna, Austria

DOI: $10.2507 / 29$ th.daaam.proceedings. 157

\begin{abstract}
Throttle valves are integral part of pumping systems, oil production and other industries. A model for throttle control system for centrifugal pump is proposed. Specific stepper motor based model is developed to provide all necessary possibilities for simulation. The model consists of several main components: stepper motor, control system, gear box, centrifugal pump, a fluid reservoir, pipeline, regulation valve, and measuring equipment. To analyze the developed model, a series of simulations were conducted. The simulation shows that the designed model is precise and easy to tune. The proposed model of the electric drive can be used as a tool for validating different control modes for centrifugal pump systems.
\end{abstract}

Keywords: valves; centrifugal pump; Matlab/Simulink; modelling; simulation

\section{Introduction}

According to recent statistical information in the European Union, approximately $70 \%$ of total generated electrical energy is consumed by electric drive systems. It makes centrifugal pump system a subject of intensive study for efficiency improvement. In fact pumping systems consume from $10 \%$ to $40 \%$ of total produced electricity [1]. Such wide scale use of centrifugal pumps leads to the fact that optimization possibilities of these systems are highly important [2].

One of the considerable parts of the centrifugal pumping system is a valve that is mainly used for throttling to control either the pressure or flow of a fluid flowing through the system. The main task of the centrifugal pump is to raise the energy of a liquid, centrifugal machine converts the energy of prime mover into the pressure energy of a liquid that is being pumped. The important part of a centrifugal machine is the impeller that converts the energy. Liquid enters the pump from its stationary part, called suction side and leaves it from so-called discharge side. Pumping systems are used for various applications in the industrial operations that include variable loads. During such processes, the value of flow varies in wide ranges. 
Thus, these types of industrial processes frequently require either pressure or flow control to achieve maximum efficiency and quality. The main goal of the throttle valve is to maintain the desired level of flow or pressure in a pumping system, or to change it within determined borders. The importance demand of high performance for pumping systems has seen electronic throttle valves become more widely used in the industry [3] and [4]. The electronic throttle control (ETC) is usually an electric motor-driven valve which regulates fluid inflow or outflow of the pumping system. The ETC system positions the throttle valve according to the reference opening angle provided by the operator or automated control system.

Modelling and simulation play an important role during system development. It is related to the fact that the design of valves and performance prediction process is still relatively complicated. Mainly it is due to the great number of parameters that are used in the pumping processes. One of the solutions is to use physical prototypes to test developed systems but the disadvantage of this method is significant time and cost of creating these prototypes. There are various methods of pump system simulation [5]. The most common method of simulation is by using the Simulink software. Different simulations are done by Simulink ranging from pump system simulation to production optimization [6], [7].

The main purpose of this paper is to represent the model of the valve control system for throttling that is designed to study processes related to pressure regulation and stabilization at a determined level or pressure regulation in accordance with needs of some industrial conditions. The main advantage of the designed model is that it contains standard functional blocks and, therefore, is easy to readjust for various pumping systems with different parameters. Also the model includes control system for a stepper motor that plays a role of actuator. Some authors prefer to use specific models [8]. It improves accuracy but at the same time makes the model more complicated. By using standard functional blocks, it becomes possible to achieve high performance and speed of simulation. The control unit of a model allows tuning the angle position of a valve quite precisely. It also helps to achieve the main goal of current research work, to create fast, precise and at the same time easy to tune model of the throttle valve for a pumping system.

\section{Valve control of the centrifugal pump system}

A conventional topology of the centrifugal pumping system with valve control possibilities consists of several main components, Fig.1:

- Pipeline for fluid transportation,

- Centrifugal pump,

- Variable speed drive (VSD),

- Programmable Logic Controller (PLC),

- Feedback with a pressure sensor,

- Regulation valve.

The system consists of the centrifugal pump directly connected to induction motor that is fed by the power converter. The supply grid is connected to the power converter. A power converter, induction motor and the programmable logical controller (PLC) represent main parts of VSD. The liquid enters the centrifugal pump along the rotating axis. This side is called suction side of the pump and after acceleration by the impeller, it flows outward into a diffuser from which it exits the pump. The main purpose of the impeller is to convert the rotation energy into liquid's kinetic energy. Every centrifugal pump can be described with the help of its main parameters, capacity $Q\left(\mathrm{~m}^{3} / \mathrm{s}\right)$, energy head $H(\mathrm{~m})$ and pressure $p$ (bar) at a certain rotational speed $n(\mathrm{rpm})$. Every manufacturer usually supplies pumps with manuals that include working characteristics.

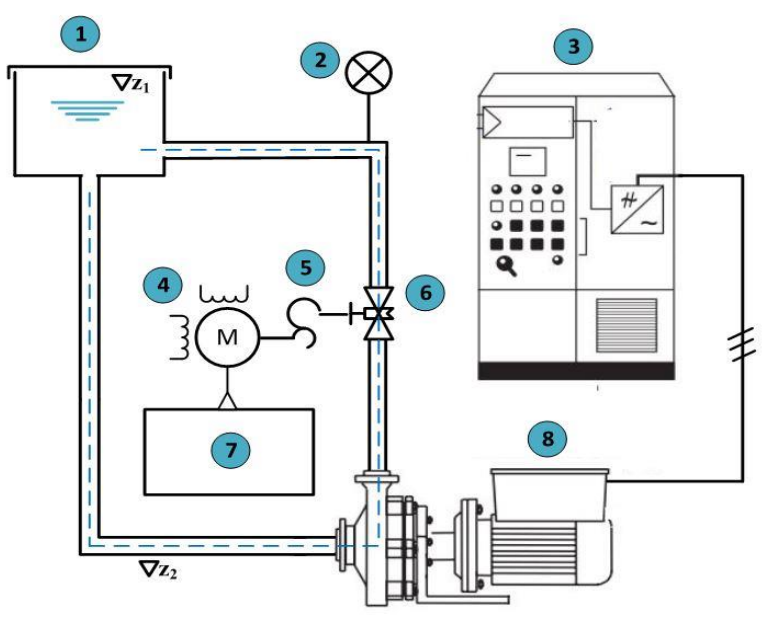

Fig. 1. The functional diagram of ETC and pumping system, (1) - liquid tank, (2) - pressure sensor, (3) - frequency converter, (4) - stepper motor, (5) - gearbox, (6) - throttle valve, (7) - control unit, (8) - centrifugal pump and induction 


\section{Structure of the Simulink model}

The stepper motor based drive system for valve throttling is simulated using MATLAB Simulink's SimPowerSystems simulation engine [9]. The stepper motor model consists of a permanent magnet stepper motor block, a driver block, a signal builder block, signal converter blocks, a DC voltage and a scope that gives the results of the simulation. The model consists of two main subsystems. The structure of the developed Simulink model is shown in Fig. 2. The model consists of two sub-blocks Figs. 3 and 4.

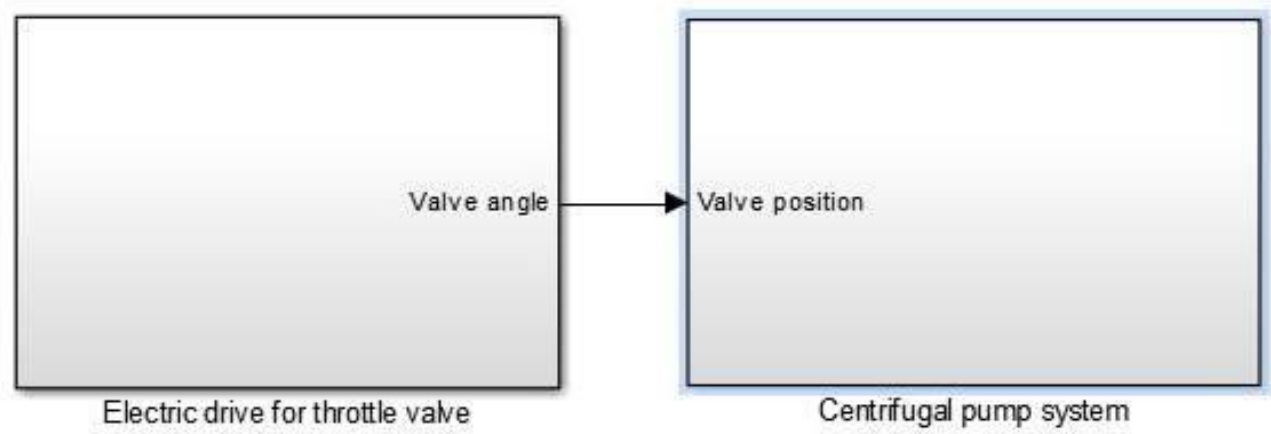

Fig. 2. Sub blocks of the developed model

Fig. 2 represents two main sub-blocks of the developed model. The second block contains ideal angular velocity source from Simulink library that allows setting a desired speed of the pump. This function block generates speed proportional to an input signal. In addition, sub-block contains centrifugal pump, and pressure-flow measuring tools, Fig. 5. Measuring blocks contain special converter block that transfers measured numerical values into physical values. These values later are stored in the memory and can be used for graphical plotting [10].

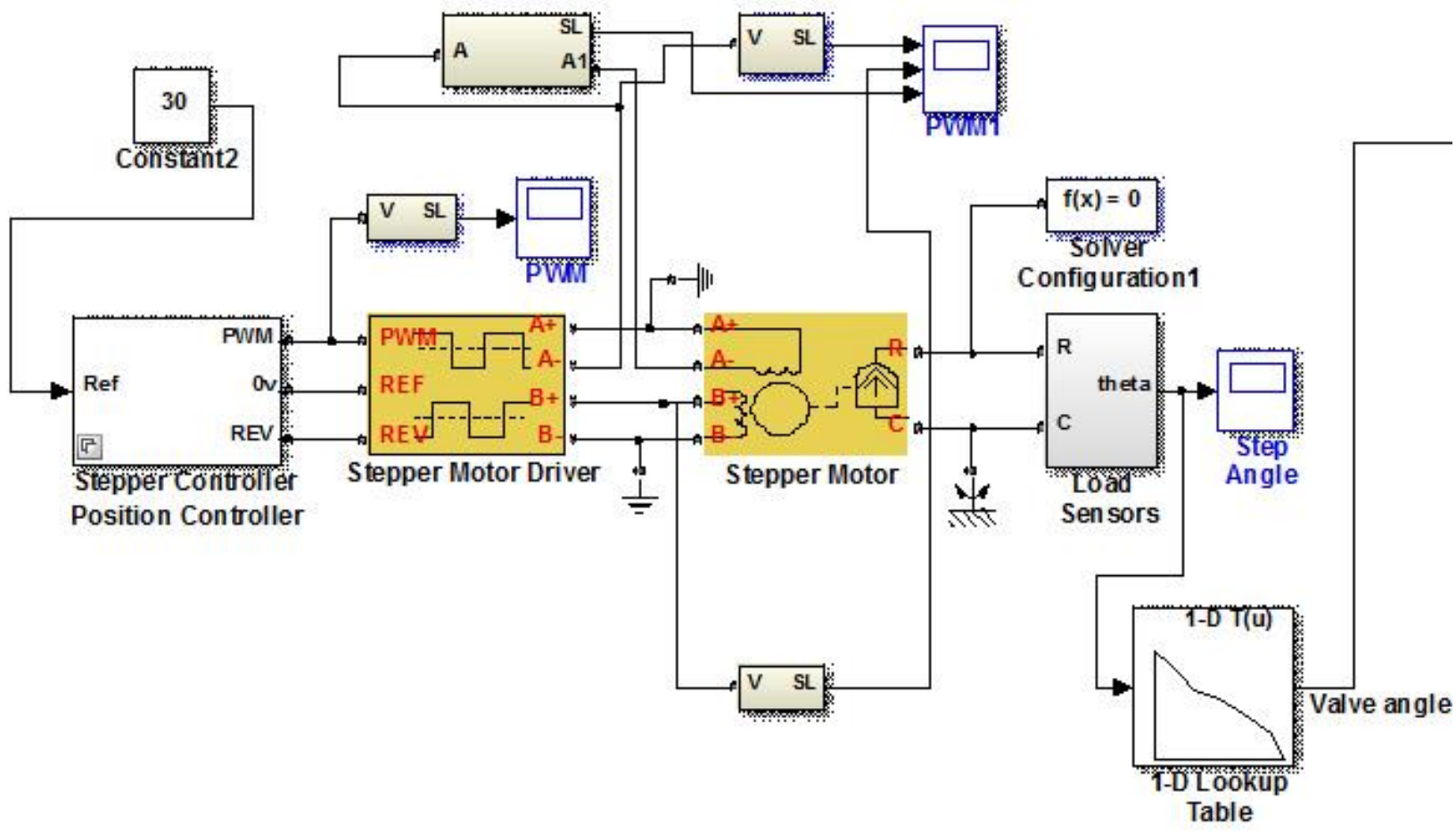

Fig. 3. First sub block

First sub-block plays the role of a control system. The reference control signal is connected to the position controller. The output signal of position controller is later connected to the stepper motor drive. Here, the DC voltage source is feeding the controlled PWM voltage block. This block is a source of pulse-width modulated voltage. The voltage on the output of the block is calculated according to the reference voltage across its input pins +ref and -ref. The REF and PWM outputs are directly connected to appropriate input pins of the H-bridge [11], [12]. Thus, this block helps to operate the stepper motor and position the shaft in accordance to reference signal. 


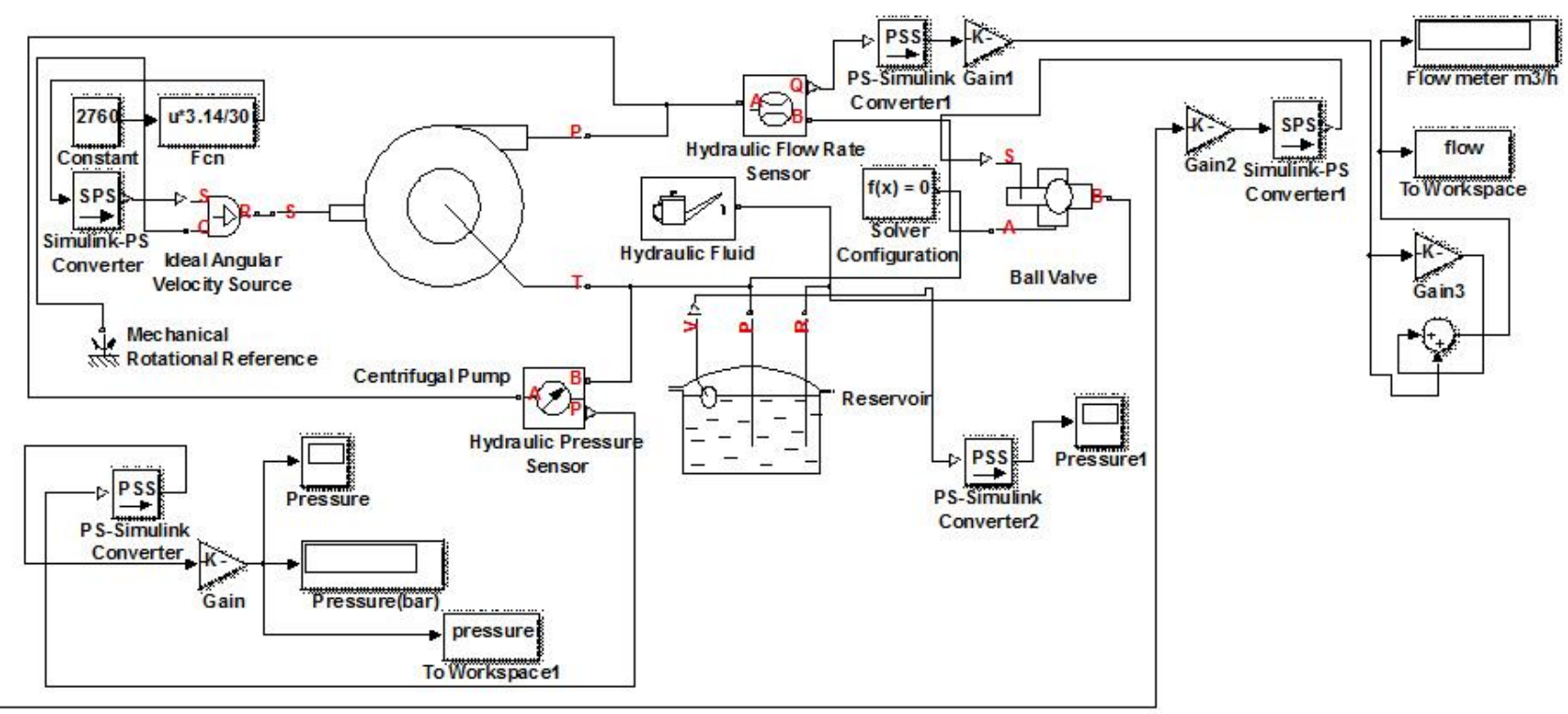

Fig. 4. Second sub block

The mathematical modelling equations for a stepper motor are given below.

$\frac{d i_{a}}{d t}=\frac{U_{a}+k \omega \sin (N \Theta)-R i_{a}}{L}$

$\frac{d i_{b}}{d t}=\frac{U_{b}+k \omega \sin (N \Theta)-R i_{b}}{L}$

$\omega=\frac{d \Theta}{d t}$

$J \frac{d \omega}{d t}=T_{e}-B \omega-T_{L}$

Where $i_{b}$ is the current in phase $\mathrm{B}, i_{a}$ is the current in phase A. $U_{a}$ is the voltage in phase $\mathrm{A}, U_{b}$ is the voltage in phase B. $L$ is the inductance of the winding and $k$ is an electromotive force constant. $N$ is the rotor teeth number, $\omega$ is the rotor speed and $\theta$ is the rotor position, $J$ is a total inertia, $T_{e}$ is an electrical torque, $B$ is a total friction coefficient. Equations (1), (2) are electrical equations and (3), (4) mechanical of the simulated stepper motor. The variations of inductance and magnetic coupling between the phases A and B are not taken into consideration in this model. The parameters of the simulated motor are given in the Table1.

\begin{tabular}{|c|c|c|}
\hline Specification & \multicolumn{2}{|c|}{ Bipolar } \\
\hline Connection type & Serial & Parallel \\
\hline Voltage, V & $10-24$ & $10-24$ \\
\hline Current/Phase, $\mathrm{A}$ & 2.12 & 4.24 \\
\hline Resistance, $\Omega$ & $2.6 \pm 15 \%$ & $0.65 \pm 15 \%$ \\
\hline Inductance, $\mathrm{mH}$ & $12.8 \pm 20 \%$ & $3.2 \pm 20 \%$ \\
\hline Torque, $\mathrm{Nm}$ & 3.54 & 3.54 \\
\hline
\end{tabular}

Table 1. ST6018L3008-A

\section{Simulation results}

After all stepper motor parameters of the stepper motor are entered in the model it is ready to be launched for the simulation. Time for simulation execution is defined to be 1 second. According to the reference signal the stepper motor rotates the throttle valve to the desired position thus controlling the pressure in the centrifugal pump system. To estimate the performance curve of the centrifugal pump system during throttling control several parameters were measured. 
Fig. 6 shows that when the valve angle is close to $90^{\circ}$, the pressure reaches its maximum level and the flow the minimum level. From the simulation results is shown in Fig. 5 it can be concluded that voltage of both winding of the stepper motor is around $12 \mathrm{~V}$ and the winding current does not exceed the level of $2.5 \mathrm{~A}$.
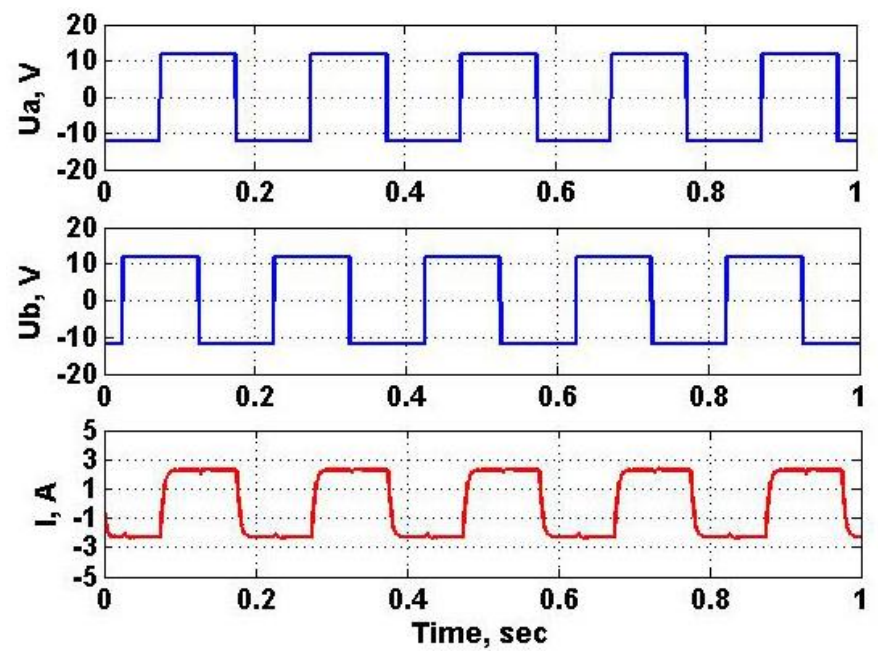

Fig. 5. Voltage and current diagrams
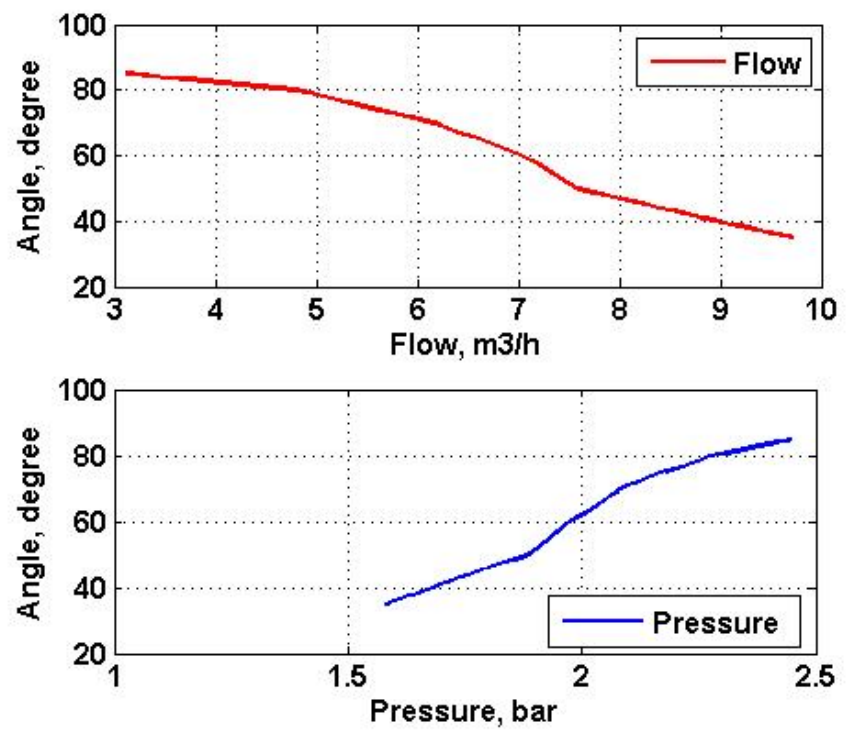

Fig. 6. Diagrams of valve angle/flow and valve angle/pressure dependences

Fig. 7 shows that the developed electric drive is fast enough to open the valve less than in 1.5 seconds. During operation in real conditions, it is not necessary to change the angle so fast and the main operation range lies between $60^{\circ}$ and $85^{\circ}$ for the experimental centrifugal pump setup.

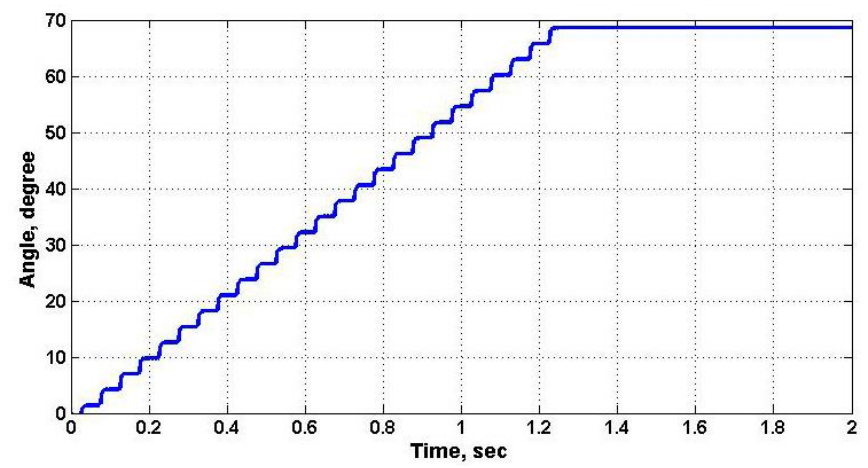

Fig. 7. Time response of valve angle control 


\section{Conclusion}

The model of an electric drive system based on a stepper motor for a throttling valve is proposed. The system can be used for pressure and flow maintenance in pumping applications. Despite the fact that there are different types of electric valves, there is still a need for a more flexible, accurate and reliable control methods for them. Nevertheless, the model was developed for a centrifugal pump system it can be useful for simulation of valve control in any other hydraulic application that involves throttling. The proposed system of an electric drive and related control approaches have some advantages for pressure maintenance. For instance, the system can be supplied with remote control possibilities. The electric drive system can be suitable for small-scale applications due to low cost and control simplicity. The stepper motor based model was designed for low torque applications but the same approach can be implemented for a wide range of throttling valves.

The simulations proved that the system is capable of maintaining the desired level of pressure in a broad range. It can help to control the reference pressure level and to avoid emergencies in the pipeline during the operation of the water distribution system when the pressure varies unpredictably or exceeds the limits.

Developed model will be used as a simulation tool for prototyping of the valve control system for a real experimental test bench imitating the circulating pumping system. It is expected that with the help of the model it will be easier to find optimal control parameters and improve existing test bench by automating the experimental process. Particularly it will help to adjust the position of the valve, also, record and display the valve angle in graphical and numerical forms.

\section{References}

[1] F. J. T. E. Ferreira, J. A C. Fong and A. T. De Almeida, (2011). "Ecoanalysis of variablespeed drives for flow regulation in pumping systems," Industrial Electronics, IEEE Transactions vol. 58, no. 6, pp. 2117-2125

[2] A. T. De Almeida, F. J. T. E. Ferreira, and J. A. C. Fong, (2011). "Standards for Efficiency of Electric Motors," IEEE Ind. Appl. Mag., vol. 17, no. 1, pp. 12-19

[3] X. Yuan, Y. Wang and L. Wu (2008): SVM-based approximate model control for electronic throttle valve, IEEE Transactions on Vehicul Technol, vol. 57, pp. 2747-2756

[4] Yuan and Y. Wang (2009): A novel electronic throttle valve controller based on approximate model method, IEEE Transactions on Indus Electron, vol. 56, pp. 883-890

[5] L. Gevorkov, V. Vodovozov, T. Lehtla and Z. Raud, (2015). "PLC-based hardware-in-the-loop simulator of a centrifugal pump," 2015 IEEE 5th International Conference on Power Engineering, Energy and Electrical Drives (POWERENG), Riga, pp. 491-496

[6] X. Qiu, L. Chen, and W. Jiang, (2015). "Simulation of the Flow Control of Radial Piston Pump Based on Simulink," in 2010 2nd International Conference on Information Engineering and Computer Science, pp. 1-3

[7] Ojstersek, R.; Buchmeister, B. (2017). Use of Simulation Software Environments for the Purpose of Production Optimization, Proceedings of the 27th DAAAM International Symposium, 2017, Vienna, Austria, ISBN 978-3902734-11-2, ISSN 1726-9679, Katalinic, B. (Ed.), pp.0751-0758, DOI: 10.2507/27th.daaam.proceedings. 106

[8] J. Ghafouri and H. Khayatzadeh, (2012). "Dynamic Modeling of Variable Speed Centrifugal Pump Utilizing MATLAB/SIMULINK," International Journal of Science and Enineering. Investigation, vol. 1, no. 5, pp. 1-7

[9] Hoang Le-Huy, P. Brunelle and G. Sybille, (2008). "Design and implementation of a versatile stepper motor model for simulink's SimPowerSystems," 2008 IEEE International Symposium on Industrial Electronics, Cambridge, pp. 437-442

[10] L. Gevorkov, I. Bakman, V. Vodovozov, (2014). "Hardware-in-the-loop simulation of motor drives for pumping applications," Electric Power Quality and Supply Reliability Conference PQ 2014, Rakvere, Estonia, pp. 1 - 6

[11] L. Gevorkov, A. Rassõlkin, A. Kallaste and T. Vaimann, (2018) "Simulink based model of electric drive for throttle valve in pumping application," 2018 19th International Scientific Conference on Electric Power Engineering (EPE), Brno, pp. 1-4

[12] D. P. Atherton, G. W. Irwin, (2007). "Stepping motors a guide to theory and practice", $4^{\text {th }}$ Edition, The Institute of Engineering and Technology 